\title{
INVESTIGATION IN SPREADING UNIFORMITY OF GRANULAR MANURE
}

\author{
Egle Jotautiene $^{1}$, Vaidas Bivainis ${ }^{1,2}$, Raimonda Zinkeviciene ${ }^{1}$, Ramunas Mieldazys ${ }^{1}$ \\ ${ }^{1}$ Vytautas Magnus University, Lithuania; ${ }^{2}$ Kaunas University of Technology, Lithuania \\ egle.jotautiene@vdu.lt, vaidas.bivainis@ktu.lt, zinkevicieneraimonda@gmail.com, \\ ramunas.mieldazys@vdu.lt
}

\begin{abstract}
Recently, centrifugal fertilizer spreaders of various manufacturers are widely used for spreading granular organic fertilizers on the soil surface. In the technical literature or instructions is a lack of recommendations from the manufacturers of fertilizer spreaders how to set the parameters for granulated manure to achieve the required amount of fertilizer dispersion (spread) and the required uniformity of spread. This article analyzes the uniformity of spreading organic granulated manure compost fertilizers in soil by a centrifugal double disc fertilizer spreader. Two types of manure pellets of different geometric characteristics were investigated for real outdoor spreading experiments, and blades of different lengths were chosen. From the analysis of the presented research results, it was determined that the centrifugal fertilizer spreader can be used to disperse (spread) granular cylindrical organic fertilizers. Also, from the obtained results a significant difference was found of spread between the used different diameters and length granules. In this article, it can be said that beside the mentioned and investigated fertilizer spreader parameters for spreading uniformity improvement it needs to take into account unexpected factors of the environment, like the wind direction and strength, pellet size, pellet size distribution, angle of spreading blade, etc.
\end{abstract}

Keywords: granular manure fertilizer, geometrical characteristics, spreading, spreader.

\section{Introduction}

Fertilization, among other agro-technical measures (crop rotation, maintenance, tillage, sowing) is considered to be the most effective way to improve the plant fertility and yield quality. Natural fertilizers are the most organic with a high concentration of nutrients. They are obtained by natural proceeding of organic elements from animal waste or vegetable humus. Organic granulated fertilizers contain beneficial substances that cause and develop microorganisms and biological bacteria that are beneficial to soil and plants. Granulated manure fertilizers do not have pathogenic microflora, weed seeds, pathogenic ova, or larvaes. Better physicomechanical properties are acquired in the granular form: increased density of materials, volumetric density, mechanical durability, static strength, etc. Granulated products are easier to handle, transport, and use in various technological processes, such as spreading in soil. One of the main advantages of pellet organic fertilizers is the fact that much less fertilizer is required compared to traditional compost and biological humus.

There are no special machines for spreading granular cylindrical organic fertilizers in the soil. Also, there is no rational recommendation of how granular cylindrical organic fertilizer should be spread. Farmers usually use mineral fertilizer spreaders to spread such fertilizers, although the mechanical-physical properties of the organic fertilizer differ significantly from those of mineral fertilizers. Granular organic fertilizers are usually cylindrical 4-6 $\mathrm{mm}$ in diameter, mineral fertilizers spherical. The density of the fertilizer also varies, so the fertilizer has a different aerodynamic drag coefficient. These differences can lead to losses in the application of the same technology to different types of fertilizers. Fertilizers can be spread unevenly, the fertilizer does not reach the required working width, the fertilizer rate is not accurately determined, and the fertilizer is too finely crushed. Crop yields are affected by uneven fertilizer applications. It reduces fertilizer use efficiency and profitability, increases nutrient losses and environmental hazards $[1 ; 2]$. Research is needed to determine the exact operating parameters of a mineral fertilizer spreader, when spreading cylindrical organic fertilizers.

Research has shown that the uniformity and accuracy of the application of spreading materials, including granular fertilizers, to the ground are largely dependent on the parameters of the centrifugal disc - the height (height), shape, diameter, number of blades, their placement, shape, length, placement angle and the material of which they are made [3]. Studies have found that the fertilizer is spread evenly with eight blades [4]. The tests used hollow square blades to distribute the fertilizer more evenly than flat blades. The aim of this work was to investigate the spread of granular manure on the soil surface by adjusting the fertilizer rate and driving speed to achieve uniform distribution using a fertilizer centrifugal spreader. 


\section{Materials and methods}

Cylindrical pellets with a diameter of $4 \mathrm{~mm}$ and $6 \mathrm{~mm}$ were used for the experimental studies of spreading granulated fertilizers. The maincharacteristics of these pallets are shown in Table 1.

Table 1

Main properties of granulated manure pellets

\begin{tabular}{|c|c|c|}
\hline Properties & 4 mm pellets & 6 mm pellets \\
\hline Pellet diameter, $\mathrm{mm}$ & $4.75 \pm 0.12^{*}$ & $5.28 \pm 0.80$ \\
\hline Pellet length, mm & $7.88 \pm 0.59$ & $10.38 \pm 0.73$ \\
\hline Quantity of dry material, \% & $90.0 \pm 4.9$ & $88.0 \pm 4.7$ \\
\hline Density, $\mathrm{kg} \cdot \mathrm{m}^{-3}$ & $650.0 \pm 27.0$ & $700.0 \pm 15.0$ \\
\hline
\end{tabular}

*Confidence interval at significance level $\alpha=0.05$

Granule diameter and length measurements were made with a Mitutoyo digital caliper, randomly selecting about 500 beads. As it is shown in Table 1, granules of similar density, but different diameters and lengths were used to determine the effect of the diameter and length of the granules on uniform application of this fertilizer [5]. In Fig. 1 the general view of pellets of $4 \mathrm{~mm}$ diameter is given.

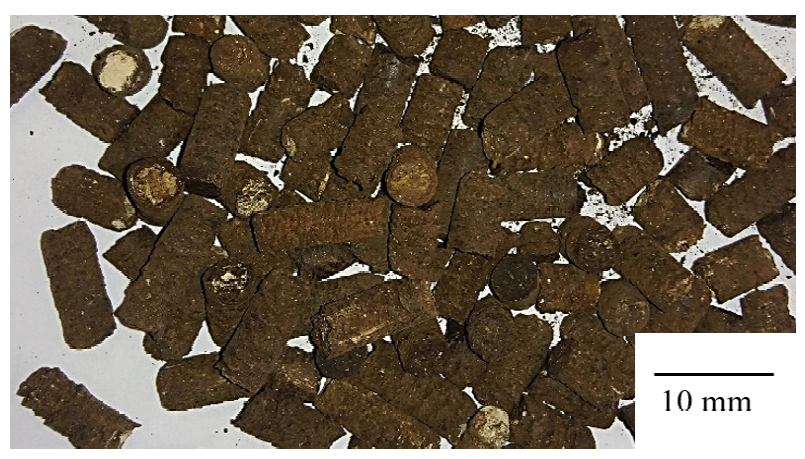

Fig. 1. View of $\mathbf{4} \mathbf{~ m m}$ diameter granulated manure pellets

Spreading of these two different diameter pellets was performed by using the centrifugal mineral fertilizer spreader. The main characteristics of this spreader are as follows: 1) working spreading width 10-36 m; 2) fertilizer hopper capacity 12001 [6]. Granulated manure fertilizer in the spreader hopper was evenly distributed, not compressed, and not falling. Spreading was done with 29 and $41 \mathrm{~cm}$ long spreading disc blades, their tilt angle was set according to the fertilizer manufacturer's recommendations for mineral fertilizer application. For the purpose to check the tilt angle of the blades, several preliminary spreads of granular fertilizers were performed. The fertilizer shutter position and the spread rate were chosen at $200 \mathrm{~kg} \cdot \mathrm{h}^{-1} \mathrm{a}$ in the centrifugal fertilizer spreader according to the manufacturer's recommendations. In order to determine the effect of the tractor spreading speed on the spreading and uniformity of the spreading, the tractor was moved at 8 and $10 \mathrm{~km} \cdot \mathrm{h}^{-1}$.

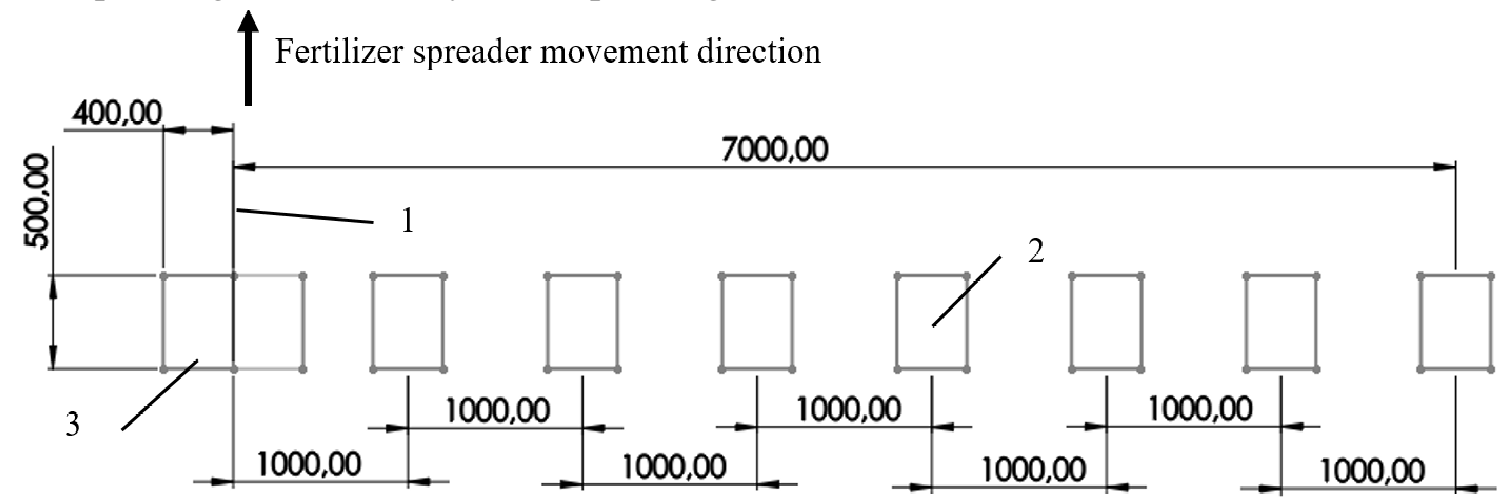

Fig. 2. Schematic view of pellet collection boxes positioning: 1 - center position of the fertilizer spreader; 2 - collection box (total quantity - 16); 3 - in the center two collection boxes are placed (for simplification here are shown 9 boxes; total spreading width is $14 \mathrm{~m}$ ) 
Fertilizer spreading was carried out on the farm according to the method of LST EN 13739 - 2: 2012 (EN 13739 - 2: 2011 (E)). The field of spreading was visually smooth with no noticeable tilt angle.

The research was accomplished in October 2019. The weather was clear with the wind speed below $2 \mathrm{~m} \cdot \mathrm{s}^{-1}$, the air temperature was around $16{ }^{\circ} \mathrm{C}$ and the relative humidity was around $31 \%$. To determine the amount of granular fertilizer to be applied, 16 units of fertilizer collection boxes were positioned perpendicular to the direction of spreading. The parameters of these boxes were as follows: width $-400 \mathrm{~mm}$, length $-500 \mathrm{~mm}$, and depth $-100 \mathrm{~mm}$. The layout of the collection boxes is shown in Fig. 2, only half of the boxes are presented to ensure the symmetry of the diagram. As it is shown in this scheme, in the center, two boxes are positioned next to each other around the middle of the spreader (these two boxes are labeled zero in the results section), and each subsequent box is spaced by $1 \mathrm{~m}$.

The total spreading width was $14 \mathrm{~m}$. The boxes were set in one row, and the fully operated spreader was moving about $5 \mathrm{~m}$, while it reached these boxes. At least 6 spreading tests were done.

The amount of fertilizer collected in the boxes was weighed with Kern electronic scales to the accuracy of $0.1 \mathrm{~g}$ after each spreading test.

\section{Results and discussion}

The effect of the size and length of the fertilizer granules on the investigated fertilizer application uniformity and application rate is shown in Fig. 3. There are presented the histograms of the granule length distribution frequency.

a)

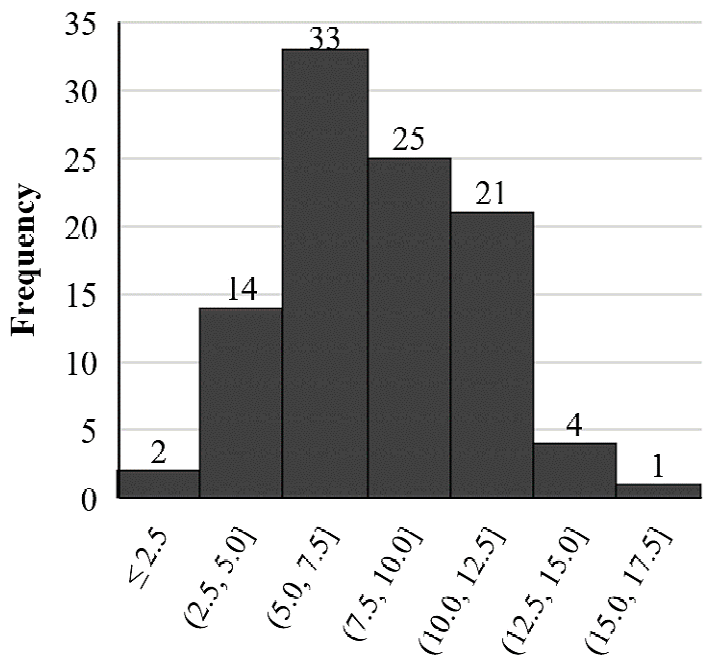

$4 \mathrm{~mm}$ diameter pellet lengt, $\mathrm{mm}$ b)

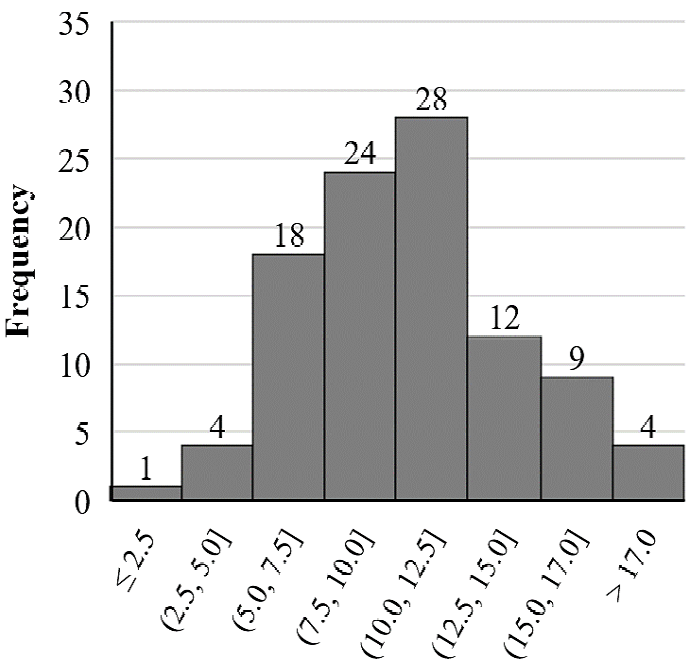

$6 \mathrm{~mm}$ diameter pellet lengt, $\mathrm{mm}$

Fig. 3. Frequency histograms of pellet length distribution: a) $-4 \mathrm{~mm}$ and b) $-6 \mathrm{~mm}$ diameter pellets

As it is showed in these histograms, the distribution of the pellet lengths is visually close to the Normal distribution. Pellets of $4 \mathrm{~mm}$ in diameter are shorter, predominant length of the pallets 5.0$12.5 \mathrm{~mm}$ (about $78.9 \%$ of all granules). As for larger diameter granules - they are a little bit longer, with a predominant length of 5.0-15.0 mm (about $82.2 \%$ of all granules). From these results, it is assumed that with the same spreading parameters of these pellets, the $6 \mathrm{~mm}$ diameter pellets should be spread further or spread more at the edges of the spreading field.

The results of the spreading of the granular fertilizer at the tractor moving speed of $8 \mathrm{~km} \cdot \mathrm{h}^{-1}$ are shown in Fig. 4. The zero position of the graph on the axis of the abscesses represents the two central fertilizer accumulation boxes, while the 7th and -7th positions show the side boxes. The total width of the fertilizer application was $14 \mathrm{~m}$. The graph shows the average weight of accumulated fertilizer from each box without converting this amount to the application rate in $\mathrm{kg} \cdot \mathrm{h}^{-1} \mathrm{a}$, because the values presented are analogous in nature and trend. 
As it may be seen from the results, the amount of granular fertilizer distributed over the spreading width was as follows: mostly in the center and the least in the edges [4]. It was found that the distribution of the pellet content over the spreading width was quite close to the quadratic polynomial. For the granules of $4 \mathrm{~mm}$ diameter, the coefficient of determination is $R^{2}=0.40$, while for the $6 \mathrm{~mm}$ granules it is $R^{2}=0.82$.

It can be stated that, using this model of spreading fertilizers, intermediate results can be calculated with a probability of $82 \%$ for the pallets of $6 \mathrm{~mm}$ diameter.
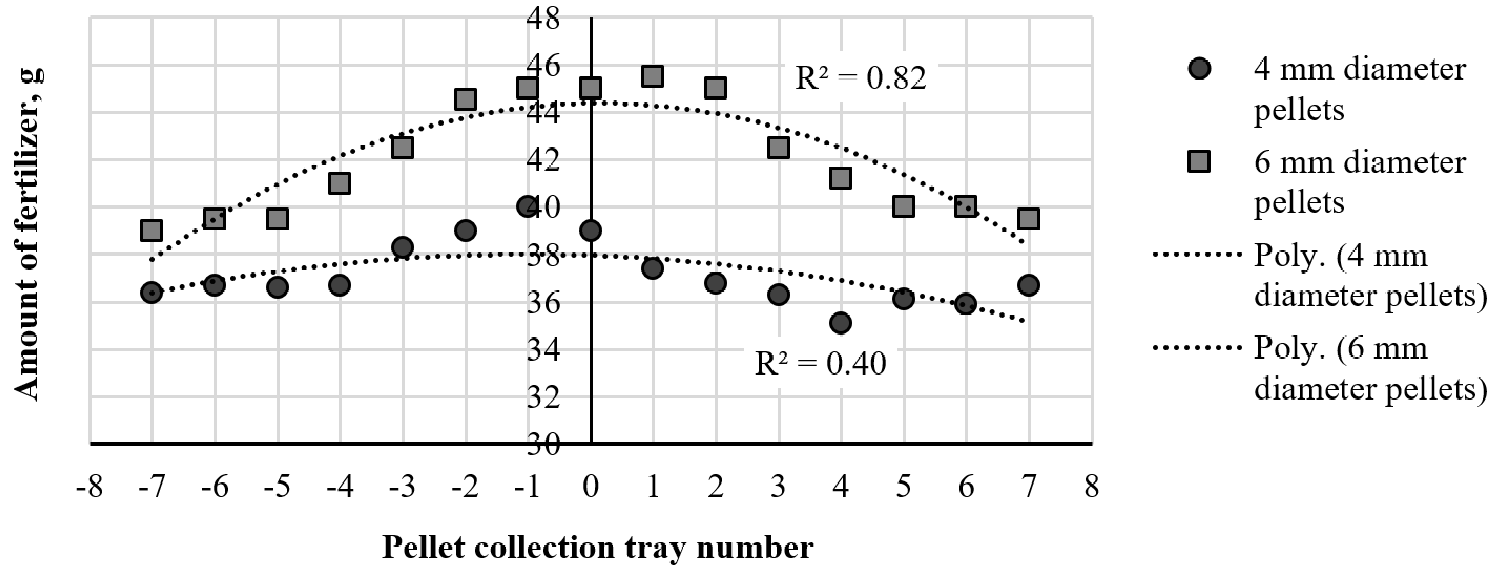

\section{Fig. 4. Distribution of $4 \mathbf{m m}$ and $6 \mathbf{m m}$ diameter granulated manure pellets at the tractor $8 \mathrm{~km} \cdot \mathrm{h}^{-1}$ movement speed}

A statistical comparison of the mean values of both pellet types resulted in a statistically significant difference between the fertilizer application rate of 4 and $6 \mathrm{~mm}$ diameter with a significance level $\alpha=0.05$. The spread rate of the $6 \mathrm{~mm}$ diameter fertilizers was about $11.5 \%$ higher than the $4 \mathrm{~mm}$ diameter granular manure fertilizers, based on the average of all boxes. It has also been found that the distribution of the $4 \mathrm{~mm}$ diameter pallets was "flatter" $(6.3 \%$ less at the edges than in the center) compared to the $6 \mathrm{~mm}$ pallets ( $12.8 \%$ less at the edges than in the center).

In Fig. 5 the data of both types of pellet spreading are given, with the tractor moving at $10 \mathrm{~km} \cdot \mathrm{h}^{-1}$ speed. It was found that the coefficient of determination for the distribution of the pallets of $4 \mathrm{~mm}$ data corresponds to the quadratic polynomial of $R^{2}=0.63$, and the coefficient of determination of the pallets of $6 \mathrm{~mm}$ spreading is $R^{2}=0.76$. Thus, from these test results, it is possible to calculate the dispersion of 4 and $6 \mathrm{~mm}$ diameter at intermediate points with 63.0 and $76.0 \%$ probability. A statistically significant difference was also found between the means of the fertilizer spread rate of $4 \mathrm{~mm}$ and $6 \mathrm{~mm}$ diameter at $\alpha=0.05$. The spread rate of the $6 \mathrm{~mm}$ diameter fertilizers was about $8.0 \%$ higher than of the fertilizers with $4 \mathrm{~mm}$ diameter, based on the average of all boxes. The "flatness" of the dispersion was similar to both types of pellets and was about $8.8 \%$ lower at the edges than at the center.

From Fig. 4 and Fig. 5 it was found that the difference of the mean of fertilizer spread between the $4 \mathrm{~mm}$ diameter pellets at $8 \mathrm{~km} \cdot \mathrm{h}^{-1}$ and $10 \mathrm{~km} \cdot \mathrm{h}^{-1}$ spreading speed was statistically insignificant at $\alpha=0.05$. There was also a statistically insignificant difference in the mean of the $6 \mathrm{~mm}$ diameter pallet spreading at $8 \mathrm{~km} \cdot \mathrm{h}^{-1}$ and $10 \mathrm{~km} \cdot \mathrm{h}^{-1}$ spreader speed and $\alpha=0.05$. We can see that the diameter (and length) of the tested pellets had a significant effect on the spread amount and its distribution in the spreading width, while the moving speed of the tractor with spreading does not influence the amount of spreading of the pellets of $4 \mathrm{~mm}$ and $6 \mathrm{~mm}$ diameter. The pellet spreading uniformity in all studies is reasonably good, only a greater difference was noticed between the center and edges, while analysing the results of the test with the $6 \mathrm{~mm}$ pellets at $8 \mathrm{~km} \cdot \mathrm{h}^{-1}$ spreader speed.

These obtained research results can be used for digital modeling or field spreading of granular fertilizers, which would allow evaluating more parameters and their influence on the amount of spreading, uniformity, and so on.The quality of application of the fertilizer can be determined by numerical or experimental methods according to two indicators: the variability of fertilizer spreading, or the rate of fertilizer application. The results showed how the rate of the fertilizer recommended by 
the producers of the fertilizer spreaders in the fertilizer distribution tables is varying depending on the driving speed. It means that, although the fertilizers will be spread according to the recommendations of the producers of the fertilizer spreaders, the desired result may be not reached. It is recommended that to apply organic granular fertilizers to the soil in order to achieve even spreading, the combining of the fertilizer rate, spreading rate, and driving speed should be used.
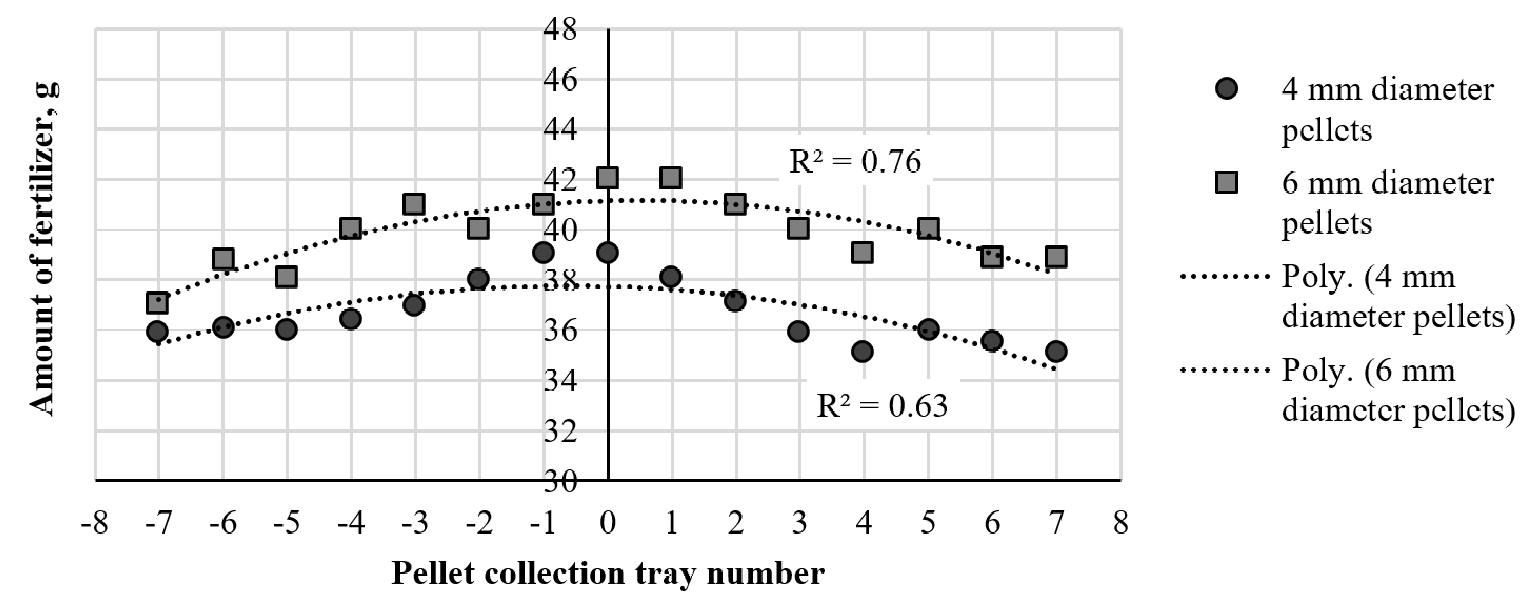
Fig. 5. Distribution of $4 \mathrm{~mm}$ and $6 \mathrm{~mm}$ diameter granulated manure pellets at the tractor
movement $10 \mathrm{~km} \cdot \mathrm{h}^{-1}$ speed

\section{Conclusions}

1. The results of granular fertilizer spreading showed that the mean values of 4 and $6 \mathrm{~mm}$ diameter and different lengths of granule spreading were significantly different. It was found that the averagespread rate of the fertilizer with a diameter of $6 \mathrm{~mm}$ was about $8.0 \%$ higher than of the fertilizer with a diameter of $4 \mathrm{~mm}$.

2. The experimental results have shown that the moving speed of the tractor with a fertilizer spreader at 8 and $10 \mathrm{~km} \cdot \mathrm{h}^{-1}$ does not have a significant effect on the mean spread rates of $4 \mathrm{~mm}$ and $6 \mathrm{~mm}$ diameter pellets.

3. From the obtained results it can be stated that the tendency of the fertilizer spreading quantity distribution over the spreading width is close to the quadratic polynomial, except the $4 \mathrm{~mm}$ pellet spreading at $8 \mathrm{~km} \cdot \mathrm{h}^{-1}$. Significant coefficients of determination were obtained: $R^{2}=0.82$, $R^{2}=0.76$ and $R^{2}=0.63$. These coefficients predicated that intermediate results can be calculated with high probability and used for digital modeling of this fertilizer application.

\section{References}

[1] Przywara A. The impact of structural and operational parameters of the centrifugal disc spreader on the spatial distribution of fertilizer. Agriculture and Agricultural Science Procedia, vol. 7, 2015, pp. 215-222.

[2] Aphale A., et al. Granular fertiliser particle dynamics on and off a spinner spreader. Biosystems Engineering, vol. 85, issue 3, 2003, p.p. 319-329.

[3] Antille, D.L., Gallar, L., Miller, P.C.H., Godwin, R.J. An investigation into the fertilizer particle dynamics off-the-disc. Applied Engineering in Agriculture, vol. 31, issue 1, 2015, pp. 49-60. doi:10.13031/aea.31.10729.

[4] Shi Yinyan, et al. Fertilization strategy and application model using a centrifugal variable-rate fertilizer spreader. International Journal of Agricultural and Biological Engineering, vol. 11, issue 6, 2018, pp. 41-48.

[5] Jotautiene E., et al. Assessment of organic granulated manure fertilizers frictional properties.Proceedings of International Conference"Engineering for Rural Development", May 23-25, 2018, Jelgava, Latvia, pp. 1539-1544.

[6] Operation Assembly manual. AMAZONE ZA-M Centrifugal Broadcaster. [online] [24.04.2020] Available at: https://info.amazone.de/DisplayInfo.aspx $? \mathrm{id}=24656$ 